\title{
A Comparative Evaluation of the Efficacy of Herbal Mouthrinse (P. granatum and S. persica) with Chlorhexidine Mouthrinse on Inhibition of Plaque and Gingivitis
}

\section{Anamika ${ }^{1}$ and Amrinder Singh Tuli $^{2 *}$}

${ }^{1}$ Post Graduate Student, Department of Periodontology, Seema Dental College and Hospital Rishikesh Uttarakhand, India

${ }^{2}$ Professor and Head, Department of Periodontology, Seema Dental College and Hospital Rishikesh, Uttarakhand, India

*Corresponding Author: Amrinder Singh Tuli, Professor and Head, Department of Periodontology, Seema Dental College and Hospital Rishikesh, Uttarakhand, India.
Received: February 20, 2021

Published: March 17, 2021

(C) All rights are reserved by Anamika and

Amrinder Singh Tuli.

\begin{abstract}
Background: In the past 40 years, Chlorhexidine has been extensively studied and used for plaque control in dentistry. It is a bisbiguanide and is considered as a gold standard antiplaque agent due to its prolonged substantivity. It has a limited use period due to its known side effects such as extrinsic stains and alterations in taste sensation. On the other hand, mouthwashes made from the herbal and plant sources containing natural occurring active ingredients provide a gentle, harmless and a trustworthy option. P. granatum and S. persica are such plant products that are known to have antiplaque effects. Moreover, their use also overcomes the side effects caused by the chlorhexidine.

Aims and Objectives: The aim of the present study was to assess and compare the antiplaque and anti-inflammatory effects of Herbal Mouthrinse containing P. granatum and S. persica with chlorhexidine mouthwash.

Materials and Methods: A number of 30 patients was included in the study. All patients underwent three different phases of treatment modalities i.e. experimental phase, no mouthwash phase and control phase. Before beginning of each phase and after completion of each phase, clinical parameters (Plaque Index, Gingival Index, oral hygiene-simplified) were assessed followed by scaling and root planing. All 30 volunteers will be subjected to 2 weeks of washout period (no mouthwash) before switchover of one phase to another phase.

Results: On interphase comparison, change i.e. decrease in the plaque index (PI), gingival index (GI), oral hygiene index-simplified (OHI-S) score was more in the experimental phase as compared to control phase and the difference was statistically significant between the two phases. On intraphase comparison, there was a highly significant decrease in all these parameters in both the phases. Conclusion: Herbal mouthwash containing P. granatum and S. persica is more efficacious in reducing the plaque index, gingival index and oral hygiene index-simplified.
\end{abstract}

Keywords: Chlorhexidine; Herbal; Mouthwash; P. granatum; S. persica; Antiplaque; Anti-Inflammatory

\section{Introduction}

Plaque control is extremely important in resolving as well as preventing the gingivitis and the conditions associated to it. The most commonly used self-performed method of plaque control is the tooth brushing that mechanically removes the dental plaque. However, in many cases this approach is not adequately performed 
by most members of the population that led to the development of the chemical plaque control in the form of mouthwashes as an adjunct to the mechanical plaque control [1]. Mouthwashes are the liquids that are rinsed in the oral cavity with the help of the perioral musculature [2]. There are mainly two types of mouthwashes available in market chemical and herbal. The chemical plaque control agents are divided into first generation such as quaternary ammonium compounds, phenols, second generation such as bisbiguanides-chlorhexidine gluconate, and third generation such as delmopinol [3]. Chlorhexidine is an example of second generation possess cationic properties. For the past 40 years it has been rigorously investigated and found that it possess superior antiplaque activity as compared to any other antimicrobial agents and hence, it is considered as a gold standard for plaque control. This is due to the fact that the other antimicrobial agents lack the substantivity and the efficacy against the microorganisms [4]. Its long term use is prohibited because of certain side effects. The most common side effect associated are extrinsic staining. Some evidence in the literature also suggests that its frequent use leads to the alterations in the taste sensations, desquamation of the oral mucosa etc [5].

With the increasing evidence about the association between oral health and the entire body health, the medications from the herbal and the plant sources containing natural occurring active ingredients provides a gentle, harmless and a trustworthy option. Their use overcomes the side effects caused by the chemical mouthwashes such as chlorhexidine [6].

P. granatum also known as Pomegranate is one such natural product that is currently extensively used for the oral health [7]. It has active components like polyphenolic flavonoids i.e. punicalagins and ellegic acid which helps to prevent gingivitis by mechanisms like oxidative stress reduction, direct anti-oxidant activity, antibacterial activity as well as direct plaque removal [8].

S. persica also called as Miswak is one of the oldest aids used for tooth cleaning. Silica present in it, functions as an abrasive material that causes stain removal as well as deposits from the surface of the tooth. Sodium bicarbonate possesses germicidal as well as abrasive effect. Tannic acid present in it has anti-plaque and antigingivitis effect [9]. Miswak sticks also reduces the virulence of the different oral pathogens. When used as a mouthwash, it has been reported to reduce the cariogenic bacteria as well as bleeding from the gingiva [10].
Thus, on the basis of these properties an attempt has been made to evaluate the efficacy of the P. granatum and S. persica with Chlorhexidine mouthrinses on inhibition of plaque and gingivitis.

\section{Materials and Methods}

The study was carried out in the Department of Periodontology, Seema Dental College and Hospital, Rishikesh, Uttarakhand with the approval of the ethical committee. The volunteer subjects were selected from the Seema Dental College and Hospital, Rishikesh. Detailed description of the study was given to each patient and a written informed consent was obtained.

\section{Subject selection}

The study included 30 systemically healthy volunteers those who fulfilled the following inclusion criteria.

\section{Inclusion criteria:}

1. Subjects having a dentition with more than 20 evaluable teeth with a minimum of five teeth per quadrant.

2. Subjects with age group between 20 - 30 years.

3. Subjects with chronic gingivitis.

Exclusion criteria:

1. Subjects with a habit of mouth breathing.

2. Subjects with a history of antibiotic therapy in the past three years.

3. Subjects with a history of systemic disease.

4. Subjects with a habit of smoking, gutkha, pan chewing etc.

5. Subjects with a history of oral prophylaxis within last six months previous to history.

6. Subjects with history of undergoing nonsurgical and surgical periodontal therapy in the last six months.

7. Subjects with orthodontic and prosthodontic appliance.

\section{Study design}

30 systemically healthy volunteers satisfying the above mentioned criteria were included in the study. At baseline, clinical parameters i.e. plaque index, gingival index and OHI-S were assessed followed by scaling and root planing. All the volunteers were then provided with the experimental mouthwash i.e. containing Pomegranate, miswak and neem and were asked to use $10 \mathrm{ml}$ of it twice daily for 14 days. At the end of the experimental phase i.e. after 14 days all the volunteers were recalled and clinical parameters i.e. 
A Comparative Evaluation of the Efficacy of Herbal Mouthrinse (P. granatum and S. persica) with Chlorhexidine Mouthrinse on Inhibition of Plaque and Gingivitis

plaque index, gingival index, OHI-S were assessed followed by scaling and root planing. The subjects were then kept on 14 days washout period in which no mouthwash was given. At the end of the 14 days i.e. the baseline for control phase, all the clinical parameters were again assessed followed scaling and root planing, followed by the control phase in which $10 \mathrm{ml}$ of control mouthwash i.e. containing $10 \%$ Chlorhexidine mouthwash was given for 14 days. At the end of the 14 days, clinical parameters were again assessed.

\section{Statistical analysis}

Statistical Product and Service Solutions (SPSS) version 21 for windows (Armonk, NY: IBM) corp software was used to analyse the data. Statistical analysis was done by using tools of descriptive statistics such as Mean and SD for representing quantitative data. Student $\mathrm{t}$ test/Unpaired ' $\mathrm{t}$ ' test was used to compare between means of two phases independent of each other (between experimental phase and control phase at each interval) in relation to mean plaque index, gingival index, OHIS-score. Paired ' $t$ ' test was used to compare mean plaque index, gingival index, OHI-S scores in each phase before and after the study period.

\section{Results}

Plaque and gingival index

On interphase comparison, at baseline, it was found that experimental phase had higher Gingival and Plaque index score as compared to control phase but the difference was not of statistical significance ( $p>0.05)$. At $14^{\text {th }}$ day, it was found that experimental phase had higher Gingival index and Plaque index score as compared to control phase but the difference was not of statistical significance ( $p>0.05)$. Change of mean GI and PI scores was more in experimental phase as compared to control phase and the difference was of statistical significance ( $<0.05$ ) (Table 1 and 2). On intraphase comparison, there was a highly statistically significant decrease in plaque and gingival index scores in both the experimental and control phase from baseline to 14 days $(\mathrm{p}<0.001)$ (Table 3 and 4).

\section{Oral hygiene index-simplified}

On Interphase comparison, at baseline, it was found that Experimental phase had higher OHI-S score as compared to Control phase and the difference was of statistical significance $(\mathrm{p}=0.001)$. At $14^{\text {th }}$ day, it was found that Experimental phase had higher OHI-S score as compared to Control phase and the difference was of statistical significance $(\mathrm{p}=0.003)$. It was found that change in OHI-S score was more in Experimental phase as compared to Control phase and

\begin{tabular}{|l|c|c|c|}
\hline \multicolumn{1}{|c|}{ GI score } & $\begin{array}{c}\text { Baseline } \\
\text { mean (SD) }\end{array}$ & $\begin{array}{c}\mathbf{1 4}^{\text {th }} \text { day } \\
\text { mean (SD) }\end{array}$ & $\begin{array}{c}\text { Change in GI score } \\
\text { (Baseline to } \mathbf{1 4}^{\text {th }} \\
\text { day) }\end{array}$ \\
\hline $\begin{array}{l}\text { Experimental } \\
\text { phase }\end{array}$ & $1.85(0.49)$ & $1.16(0.36)$ & $0.68(0.20)$ \\
\hline Control phase & $1.66(0.41)$ & $1.07(0.35)$ & $0.58(0.16)$ \\
\hline $\begin{array}{l}\text { Unpaired ' } \mathrm{t} \text { ' test } \\
\text { value }\end{array}$ & $\mathrm{t}=1.616$ & $\mathrm{t}=0.979$ & $\mathrm{t}=2.069$ \\
\hline P value & $\mathrm{p}=0.112$ & $\mathrm{p}=0.332$ & $\mathrm{p}=0.043^{*}$ \\
\hline
\end{tabular}

Table 1: Interphase comparison of mean gingival index.

\begin{tabular}{|l|c|c|c|}
\hline \multicolumn{1}{|c|}{ PI score } & $\begin{array}{c}\text { Baseline } \\
\text { mean (SD) }\end{array}$ & $\begin{array}{c}\mathbf{1 4}^{\text {th }} \text { day } \\
\text { mean (SD) }\end{array}$ & $\begin{array}{c}\text { Change in } \\
\text { PI score } \\
\text { (Baseline to } \\
\mathbf{1 4}^{\text {th }} \text { day) }\end{array}$ \\
\hline $\begin{array}{l}\text { Experimental } \\
\text { phase }\end{array}$ & $1.99(0.46)$ & $1.22(0.36)$ & $0.76(0.17)$ \\
\hline Control phase & $1.77(0.36)$ & $1.12(0.33)$ & $0.65(0.17)$ \\
\hline $\begin{array}{l}\text { Unpaired ' } \mathrm{t} \text { ' test } \\
\text { value }\end{array}$ & $\mathrm{t}=1.938$ & $\mathrm{t}=1.057$ & $\mathrm{t}=2.630$ \\
\hline P value & $\mathrm{p}=0.057$ & $\mathrm{p}=0.295$ & $\mathrm{p}=0.011^{*}$ \\
\hline
\end{tabular}

Table 2: Interphase comparison of mean plaque index score.

\begin{tabular}{|l|c|c|c|c|}
\hline \multicolumn{1}{|c|}{ GI score } & $\begin{array}{c}\text { Baseline } \\
\text { mean (SD) }\end{array}$ & $\begin{array}{c}\mathbf{1 4}^{\text {th }} \text { day } \\
\text { mean (SD) }\end{array}$ & $\begin{array}{c}\text { Paired } \\
\text { 't' test } \\
\text { value }\end{array}$ & \multicolumn{1}{|c|}{ P value } \\
\hline $\begin{array}{l}\text { Experimental } \\
\text { phase }\end{array}$ & $1.85(0.49)$ & $1.16(0.36)$ & $\mathrm{t}=6.106$ & $\mathrm{P}<0.001^{* *}$ \\
\hline Control phase & $1.66(0.41)$ & $1.07(0.35)$ & $\mathrm{t}=5.899$ & $\mathrm{P}<0.001^{* *}$ \\
\hline
\end{tabular}

Table 3: Intraphase comparison of mean gingival index score.

\begin{tabular}{|l|c|c|c|c|}
\hline \multicolumn{1}{|c|}{ PI score } & $\begin{array}{c}\text { Baseline } \\
\text { mean (SD) }\end{array}$ & $\begin{array}{c}\mathbf{1 4}^{\text {th }} \text { day } \\
\text { mean (SD) }\end{array}$ & $\begin{array}{c}\text { Paired 't' } \\
\text { test value }\end{array}$ & P value \\
\hline $\begin{array}{l}\text { Experimental } \\
\text { phase }\end{array}$ & $1.99(0.46)$ & $1.22(0.36)$ & $\mathrm{t}=7.098$ & $\mathrm{P}<0.001^{* *}$ \\
\hline Control phase & $1.77(0.36)$ & $1.12(0.33)$ & $\mathrm{t}=7.170$ & $\mathrm{P}<0.001^{* *}$ \\
\hline
\end{tabular}

Table 4: Intraphase comparison of mean plaque index score. 
the difference was of statistical significance $(\mathrm{p}=0.042)$ (Table 5). On Intraphase comparison, it was observed that decline in mean OHI-S from baseline to $14^{\text {th }}$ day was of highly statistical significance $(\mathrm{p}<0.001)$ in the both the phases from baseline to 14 days (Table $6)$.

\begin{tabular}{|l|c|c|c|}
\hline OHI-S score & $\begin{array}{c}\text { Baseline } \\
\text { mean (SD) }\end{array}$ & $\begin{array}{c}\mathbf{1 4}^{\text {th }} \text { day } \\
\text { mean (SD) }\end{array}$ & $\begin{array}{c}\text { Change in OHI-S } \\
\text { score (Baseline } \\
\text { to 14 }\end{array}{ }^{\text {th }}$ day) \\
\hline $\begin{array}{l}\text { Experimental } \\
\text { phase }\end{array}$ & $0.99(0.33)$ & $0.53(0.33)$ & $0.46(0.24)$ \\
\hline Control phase & $0.68(0.32)$ & $0.34(0.12)$ & $0.34(0.26)$ \\
\hline $\begin{array}{l}\text { Unpaired ' } t \text { ' } \\
\text { test value }\end{array}$ & $\mathrm{t}=3.681$ & $\mathrm{t}=3.058$ & $\mathrm{t}=1.769$ \\
\hline P value & $\mathrm{p}=0.001^{*}$ & $\mathrm{p}=0.003^{*}$ & $\mathrm{p}=0.042^{*}$ \\
\hline
\end{tabular}

Table 5: Interphase comparison of mean oral hygiene index-simplified score.

\begin{tabular}{|l|c|c|c|c|}
\hline OHIS-S score & $\begin{array}{c}\text { Baseline } \\
\text { mean (SD) }\end{array}$ & $\begin{array}{c}\mathbf{1 4}^{\text {th }} \text { day } \\
\text { mean (SD) }\end{array}$ & $\begin{array}{c}\text { Paired 't' } \\
\text { test value }\end{array}$ & P value \\
\hline $\begin{array}{l}\text { Experimental } \\
\text { phase }\end{array}$ & $0.99(0.33)$ & $0.53(0.33)$ & $t=5.341$ & $P<0.001^{* *}$ \\
\hline Control phase & $0.68(0.32)$ & $0.34(0.12)$ & $t=8.035$ & $P<0.001^{* *}$ \\
\hline
\end{tabular}

Table 6: Intraphase comparison of mean oral hygiene index-simplified score.

\section{Discussion}

As per the results of this study, experimental mouthwash containing P. granatum, S. persica and Neem mouthwash is more efficacious in reducing the gingival index. Rezaei $\mathrm{S}$ in their study stated that herbal mouthwash with $S$. persica extract is more efficacious than $0.2 \%$ Chlorhexidine mouthwash in reducing the scores of gingival index [11]. Champaneri H R compared the effectiveness of Camellia sinensis, P. granatum and $0.2 \%$ Chlorhexidine mouthrinse. Results stated that P. granatum and Camellia sinensis showed similar results in reducing the gingival index and were better than $0.2 \%$ Chlorhexidine [12].

The active components of the pomegranate such as polyphenolic flavonoids like ellagic acid and punicalagins prevent gingivitis by various mechanisms like direct antioxidant activity, anti-inflammatory, antibacterial effect. These effects are brought by reducing the activities of the aminotransferase which is cell injury indicator, decreasing the activity of the alpha- glucosidase and elevating the activities of the ceruloplasmin that gives protection against the oxidative stress. It also enhance the radical scavenging capacity [13]. Neem possess Catechins that have capability of reducing the oxidative burst from Polymorphonuclear leucocytes (PMNs) leading to the restriction of the inflammation [14]. Gallotannins present in miswak and neem provide anti-inflammatory, antibacterial and antioxidant properties to these extracts [15].

The results of this study showed that herbal mouthrinse was more effective in reducing the plaque index as compared to chlorhexidine mouthrinse. Similar results were shown by a study conducted by Niazi $\mathrm{F}$ in which it was stated that the mouthrinse containing $S$. persica extract is more effective in reducing the plaque index as compared to $0.2 \%$ Chlorhexidine [15].

Dandekar N V prepared the mouthwashes with the dry extracts of the neem and the mango twings and compared the plaque index and the gingival index at baseline, $7^{\text {th }}$ and after 21 days. As per the results it can be concluded that more reduction in plaque index was seen in chlorhexidine as compared to neem and mango mouthwash. Whereas no difference was seen between the neem and the mango mouthwashes [16].

Neem contains isoprenoids like nimbinin, nimbin and nimbidin that possess antibacterial activity against streptococci and also limit its adhesion to the tooth surface. Miswak shows its antibacterial effect by releasing tannins and thiocyanates which shows activity against early colonizers such as Streptococci and Porphyromonas gingivalis. Thiocyanate present in miswak exerts antibacterial properties by activating the salivary peroxidase/thiocyanate system [14]. Pomegranate stops the inter-bacterial adhesion or coaggregation of microorganisms leading to the disruption of the plaque biofilm. Pomegranate decreases the total protein levels of saliva leading to a decrease in the plaque forming bacteria [13].

In the present study, there was difference in the mean Oral hygiene index- simplified (OHI-S) score between the two phases at baseline and it was statistically significant ( $p=0.001$ ). After 14 days also the difference was statistically significant ( $p=0.003$ ). Whereas Change in mean Oral hygiene index (OHI-S) score from baseline to $14^{\text {th }}$ day was more in the experimental phase and it was also statistically significant $(\mathrm{p}=0.042)$. 
As per the results of this study, herbal mouthrinse containing $P$. granatum, $S$. persica and Neem mouthrinse is more efficacious in reducing the Oral hygiene index- simplified. Similar results were showed by a study conducted by Balappanavar A Y in which there is comparison of mouthwashes containing $0.2 \%$ Chlorhexidine, $2 \%$ neem and $0.5 \%$ tea. Results of this study showed that improvement in oral hygiene was better appreciated in mouthwashes containing neem and tea extract [17].

P. granatum mouthrinses effects the oral health by reducing the plaque and calculus formation by inhibiting the activities of the microorganisms [13]. High concentration of chlorides present in the miswak inhibit the formation of dental calculus [18]. Neem inhibits the adhesion of streptococci on the tooth surface leading to reduced plaque formation and ultimately decreased formation of calculus [19]. Balappanavar A Y on intragroup comparison of $0.2 \%$ Chlorhexidine mouthrinse, $2 \%$ neem mouthrinse and $5 \%$ tea mouthrinse stated that there was a significant reduction in Oral hygiene index- simplified in all the three groups after 3 weeks of usage [17]. Bayaty F H in a study assessed the substantivity of $10 \%$ $S$. persica extract in the oral cavity and stated that $S$. persica extracts were present in the oral cavity after 6 hours and vanished after 8 hours of expectoration [20].

\section{Conclusion}

Within the limitations of this study, it can be concluded that mouthwash containing P. granatum, S. persica and Azadirachta indica showed better reduction in plaque index, gingival index and OHIS scores in comparison to the Chlorhexidine. Studies have reported that mouthwashes containing $S$. persica has a maximum substantivity of eight hours, whereas, Chlorhexidine has a substantivity of 12 hours. So further studies are needed to be conducted to assess the efficacy and substantivity of these mouthwashes in comparison to Chlorhexidine.

\section{Bibliography}

1. Cai H., et al. "Effects of Herbal Mouthwashes on Plaque and Inflammation Control for Patients with Gingivitis: A Systematic Review and Meta-Analysis of Randomised Controlled Trials". Evidence-Based Complementary and Alternative Medicine (2020): 1-16.

2. Manipal S., et al. "The Mouthwash War Chlorhexidine vs. Herbal Mouth Rinses: A Meta-Analysis". Journal of Clinical and Diagnostic Research 10.5 (2016): ZC81-ZC83.
3. Renuka S and Muralidharan NP. "Comparison in benefits of Herbal Mouthwashes with Chlorhexidine Mouthwash: A review". Asian Journal of Pharmaceutical and Clinical Research 10 (2017): 3-7.

4. Sajjan P., et al. "Chlorhexidine as an Antimicrobial Agent in Dentistry - A Review”. OHDM 15.4 (2016): 93-100.

5. Bagchi S., et al. "Evaluation of efficacy of a commercially available herbal mouthwash on dental plaque and gingivitis: A double-blinded parallel randomized controlled trial". Journal of Indian Association of Public Health Dentistry, India 13 (2015): 222-227.

6. Kaur PK., et al. "Evaluation of Efficacy of Three Commercially Available Herbal Mouthwashes in Treatment of Chronic Gingivitis: A Comparative Clinical Study". Journal of International Dental and Medical Research 1.4 (2014): 42-46.

7. Pinni J., et al. "Antimicrobial Activity of Pomegranate (Punica granatum) Pericarp Extract against Streptococcus mutans- A Source For Natural Mouth Rinse: An In-vitro and In-vivo Study". Biomedical and Pharmacology Journal 11.4 (2018): 2025-2030.

8. Umar D., et al. "The effect of pomegranate mouthrinse on Streptococcus mutans count and salivary $\mathrm{pH}$ : An in vivo study". Journal of Advanced Pharmaceutical Technology and Research 7.1 (2016): 13-16.

9. Dahiya P., et al. "Miswak: A periodontist's perspective". Journal of Ayurveda and Integrative Medicine 3.4 (2012): 184-187.

10. Kiany F., et al. "Assessing the effect of pomegranate fruit seed extract mouthwash on dental plaque and gingival inflammation". Journal of Dental Research and Review 3 (2016): 117-123.

11. Rezaei S., et al. "Comparison the efficacy of herbal mouthwash with chlorhexidine on gingival index of intubated patients in Intensive Care Unit". Journal of Indian Society of Periodontology 20.4 (2016):404-408.

12. Champaneri H R., et al. "Effectiveness of Indigenously Prepared Punica granatum and Camellia sinensis Mouthwashes as an adjunct to Non-Surgical Periodontal Therapy: A Clinical Trial”. The Journal of Nepalese Society of Periodontology and Oral Implantology 1 (2017): 27-31.

13. Utomo $\mathrm{H}$ and Oetomo K C. "Pomegranate juice (Punica granatum) as an ideal mouthrinse for fixed orthodontic patients". Journal of Dentistry 45.4 (2012): 221-227. 
14. Tadikonda A., et al. "Anti-plaque and anti-gingivitis effect of Papain, Bromelain, Miswak and Neem containing dentifrice: A randomized controlled trial". Journal of Clinical and Experimental Dentistry 9.5 (2017): 649-653.

15. Niazi F H., et al. "Antiplaque efficacy of herbal mouthwashes compared to synthetic mouthwashes in patients undergoing orthodontic treatment: A randomised controlled trial". Oral Health and Preventive Dentistry 16.5 (2018):409-416.

16. Dandekar NV and Winnier JJ. "Assessment of Antiplaque and Anti-Gingivitis Efficacy of Mouthwashes Prepared from Neem and Mango Extracts". Front Dent 17 (2020): 1-11.

17. Balappanavar AY., et al. "Comparison of the effectiveness of $0.5 \%$ tea, $2 \%$ neem and $0.2 \%$ chlorhexidine mouthwashes on oral health: A randomized control trial". Indian Journal of Dental Research 24 (2013): 26-34.

18. Deswal H., et al. "Miswak as an alternative treatment modality in medicine and dentistry: A review". Indian Journal of Life Sciences 4.2 (2016): 6-8.

19. Lakshmi T., et al. "Azadirachta indica: A herbal panacea in dentistry - An update". Pharmacognosy Reviews 9.7 (2015): 41-44.

20. Bayaty F H., et al. "Effect of mouthwash extracted from Salvadora persica on dental plaque formation: A clinical trial". Journal of Medicinal Plants Research 4.14 (2010): 1446-1454.

\section{Assets from publication with us}

- Prompt Acknowledgement after receiving the article

- Thorough Double blinded peer review

- Rapid Publication

- Issue of Publication Certificate

- High visibility of your Published work

Website: www.actascientific.com/

Submit Article: www.actascientific.com/submission.php

Email us: editor@actascientific.com

Contact us: +919182824667 